\title{
RFID-based Positioning System in Complex Environments
}

\author{
Mudrik Alaydrus \\ Universitas Mercu Buana, Jalan Meruya Selatan, \\ Jakarta, 11650 Indonesia \\ Email: mudrikalaydrus@yahoo.com
}

\begin{abstract}
For effective identification of objects, Radio Frequency Identification (RFID) is used in miscellaneous activities. In recent times, RFID is also used for positioning purposes. We show a scenario of wireless propagation in free space observed by up to eight antennas with different polarization located in different positions. In this way, the polarization and diagram radiation of the antennas will play a significant role in producing electromagnetic field in the region. In the second case, the effects of disturbances in form of metallic boxes are studied. The determination of the position is carried out by fingerprinting procedure.
\end{abstract}

Keywords: antennas; finger printing; identification; method of moment; polarization; positioning; radiation diagram; RFID; RSS; wireless.

\section{Introduction}

Since its introduction some decades ago, radio frequency identification (RFID) is implemented in many applications, which help us to do our daily activities more efficient and effective [1]. RFID is used for identifying of goods in warehouse, books in library, for controlling of personal access in buildings, for supporting the problems in supply chain of things, and other purposes [2]. An emerging application of RFID is positioning of objects, especially mobile robots $[3],[4],[5]$ and communication networks [6],[7],[8]. For indoor propagation problem, RFID based positioning systems are preferred than the GPS based counterpart [9], due to the shadowing problem of the satellite signals, which leads to intolerable results. Other indoor positioning systems are given in [10],[11]. In [12],[13] RFID systems are used for accurate positioning problems in indoor propagation. Most of publications concerning with wireless propagation problems used statistical data evaluations [5],[14],[15], and some few other used simple deterministic approach [16],[17],[18]. In this work we would like to observe the effects of antenna characteristic quantities, such as polarization/orientation and diagram radiation of the antenna in an indoor positioning system [19]. Moreover, we observe the effects of the presence of disturbances in form of metallic boxes to the accuracy of positioning. For estimating the position we use the fingerprinting approach. To produce the data base, a scenario in a free space region with dimension of $6 \mathrm{~m} \times 6 \mathrm{~m}$ is observed. Around the region we set up eight antennas in different known positions and

Received November $15^{\text {th }}, 2010$, Revised April 15 ${ }^{\text {th }}, 2011$, Accepted for publication April $25^{\text {th }}, 2011$.

Copyright (C) 2011 Published by LPPM ITB, ISSN: 1978-3086, DOI: 10.5614/itbj.ict.2011.5.2.1 
different polarization. The tag will be moved around the region. In the second case, we observe smaller regions; however the regions contain two metallic boxes and the antennas used are directional antennas.

\section{$2 \quad$ Principles of Wireless Positioning}

For positioning purposes, three important signal characteristics can be used; the received signal strength (RSS), the angle of arrival (AOA) and the time of arrival (TOA) [20],[21]. With these characteristic quantities we can deduce information about the position of the tag attached on an object.

To implement the method angle of arrival (AOA) we need directional antennas. AOA methods are the core of direction finding (DF), which has been used for years to locate illegal transmitters or for tracking wild animals that are tagged with tiny transmitters. It requires no cooperation from the target, and any type of signal can be used, including continuous wave (CW). It also is used over wide frequency bands and ranges - from high frequency (HF) through microwave and from direct true line-of-sight to long communications distances propagated through the ionosphere. AOA is a principle component in a radar system. Using radar, only one fixed station is required to determine the location of a target in two or three dimensions. The two methods of AOA and time of flight (TOF) are employed. When using AOA alone, at least two fixed terminals are required, or two separate measurements by a single terminal in motion.

TOA (time of arrival) and TDOA (time difference of arrival) methods use relationships based on distances between a mobile station and a number of fixed terminals to determine the position coordinates of the mobile target. Data for distance estimations are derived from the arrival times of radio signal epochs at one or more receivers. The TOA method uses the transit time between transmitter and receiver directly to find distance, whereas the TDOA method calculates location from the differences of the arrival times measured on pairs of transmission paths between the target and fixed terminals. Both TOA and TDOA are based on the TOF principle of distance measurement, where the sensed parameter, time interval, is converted to distance by multiplication by the speed of propagation. In TOA, location estimates are found by determining the points of intersection of circles or spheres whose centers are located at the fixed stations and the radii are estimated distances to the target. TDOA locates the target at intersections of hyperbolas or hyperboloids that are generated with foci at each fixed station of a pair.

In applying RSS we use the condition that, signal strength at a receiver decreases as distance from the transmitter increases. If the relationship between signal strength and distance is known, analytically or empirically, the distance 
between two terminals can be determined. When several base stations and a target are involved, triangularization can be applied to determine the target's location. RSS has several advantages over the TOF methods. It can be implemented on an existing wireless communications system with little or no hardware changes. All that's needed is the ability to read a RSSI (received signal strength indicator) output that is provided on virtually all receivers, and to interpret the reading using dedicated location estimation software. Thus location capability can be added to a wireless system for very low incremental cost.

On the other hand, there are specific problems in implementing location awareness with the RSS method. Because of large variations of signal strength due to interference and multipath on the radio channel, location accuracy is generally less than what can be achieved using TOF methods. Propagation is location/environment specific, and system software usually has to be tailored to the place where the system is being used. Often, as will be shown later, a specific database must be created for a given location. In order to achieve a useful accuracy in a location system, many more fixed, or reference terminals, are required than the minimum number needed for triangulation. Orientation of a target as well as its location related to nearby objects will have an effect on the location estimation.

There are two basic classes of systems that use RSS to estimate location: those that are based on known radio propagation analytic relationships (the so-called proximity), and those that involve searching a database that is composed of measured signal strengths in a location specific survey. The latter class is often referred to as fingerprinting.

In this work we restrict our observation to RSS with fingerprinting. The data base can be produced by means of calculation or by measurements. Specially in calculating the received power as data entry in the data base several methods ranging from simplest analytical methods to sophisticated numerical hybrid methods can be used. The methodology of the positioning is comparing the measured power from the actual problem with the data base. The requirement for useful positioning is that, the actual scenario must be the same like that during the data entry, and the actual measurement must be accurate enough.

Figure 1 shows a grid structure giving possible locations in which data on received power is stored in a data base. Certainly, the accuracy of the later positioning procedure can be improved by taking a finer grid structure with the cost of bigger data base and consequently more intensive calculation for all steps in positioning procedure. 


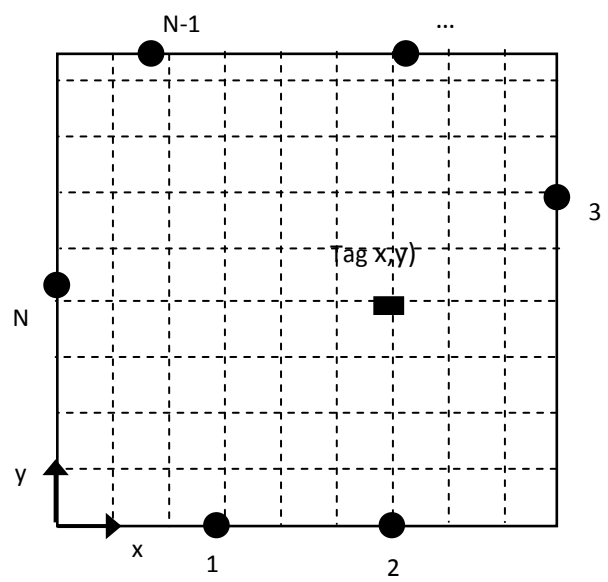

Figure 1 Positioning of tag (object) by means of $\mathrm{N}$ receiver antennas.

Having data base containing received power information in each chosen reference points, the next goal is how to determine a point if some received power information is given. This problem can be solved by a simple search method or by complicated but more efficient optimization methods. Therefore, it would be two challenges in this step, which optimization method should be taken and what kind of cost function should be used. In this work we used the brute force search method and the following least square cost functions

$$
F=\left(\sum_{j=1}^{N}\left(P_{\text {actual }}-P_{x, y, D B}\right)^{2}\right)^{1 / 2}
$$

or

$$
F=\left(\sum_{j=1}^{N}\left(2 \frac{P_{\text {actual }}-P_{x, y, D B}}{P_{\text {actual }}+P_{x, y, D B}}\right)^{2}\right)^{1 / 2}
$$

$P_{x, y, D B}$ is the power received in point x,y stored in data base, $P_{a c t u a l}$ is a given power, its location must be determined, $N$ is the number of antenna receivers used for positioning problem.

\section{$3 \quad$ Antennas in RFID}

As one of the most important part of wireless systems, antennas play a significant role in tailoring the overall performance of the RFID. Designing of antennas depends on the specifications given by the system in which the antennas embedded. Important data is certainly the frequency region of the antenna. In this work we will restrict our problems to UHF region $900 \mathrm{MHz}$ and 
use dipole antennas with length a half of wave length [22] for the first scenario. For the second scenario, we add to the dipole a planar metallic rectangular reflector in distance of a quarter of wavelength to get directional antennas. In this work we use the method of moment [22] for all antenna structures including the tag. The received power will be calculated by means of induction of the field in the remote structure, i.e. in the scattering matrix form would be S21.

\section{$4 \quad$ Simulation Results}

\subsection{Free Space Scenario}

For a detail observation we make use a special case, a region $6 \mathrm{~m} \times 6 \mathrm{~m}$ is considered here. We would like to determine the exact position of the tag inside this region. Figure 2 shows the tag at the position $(\mathrm{x}, \mathrm{y})$ in the region and around it there are eight antennas with different positions and orientations (polarizations).

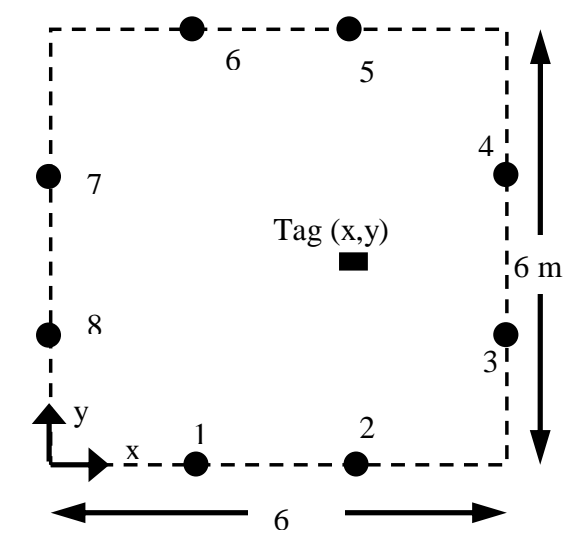

Figure 2 First observed scenario - free space case.

Table 1 Locations and polarization of receiver antennas.

\begin{tabular}{cccc}
\hline Antenna & $\mathbf{x}[\mathbf{m}]$ & $\mathbf{y}[\mathbf{m}]$ & Polarization \\
\hline 1 & 2 & 0 & $\mathrm{X}$ \\
2 & 4 & 0 & $\mathrm{Z}$ \\
3 & 6 & 2 & $\mathrm{Z}$ \\
4 & 6 & 4 & $\mathrm{Y}$ \\
5 & 4 & 6 & $\mathrm{Z}$ \\
6 & 2 & 6 & $\mathrm{X}$ \\
7 & 0 & 4 & $\mathrm{Y}$ \\
8 & 0 & 2 & $\mathrm{Z}$ \\
\hline
\end{tabular}


The Table 1 gives information about the complete position and polarization of each antenna. These antennas receive signals sent from the tag and based on the received signals the actual position of the tag should be predicted as accurate as possible.
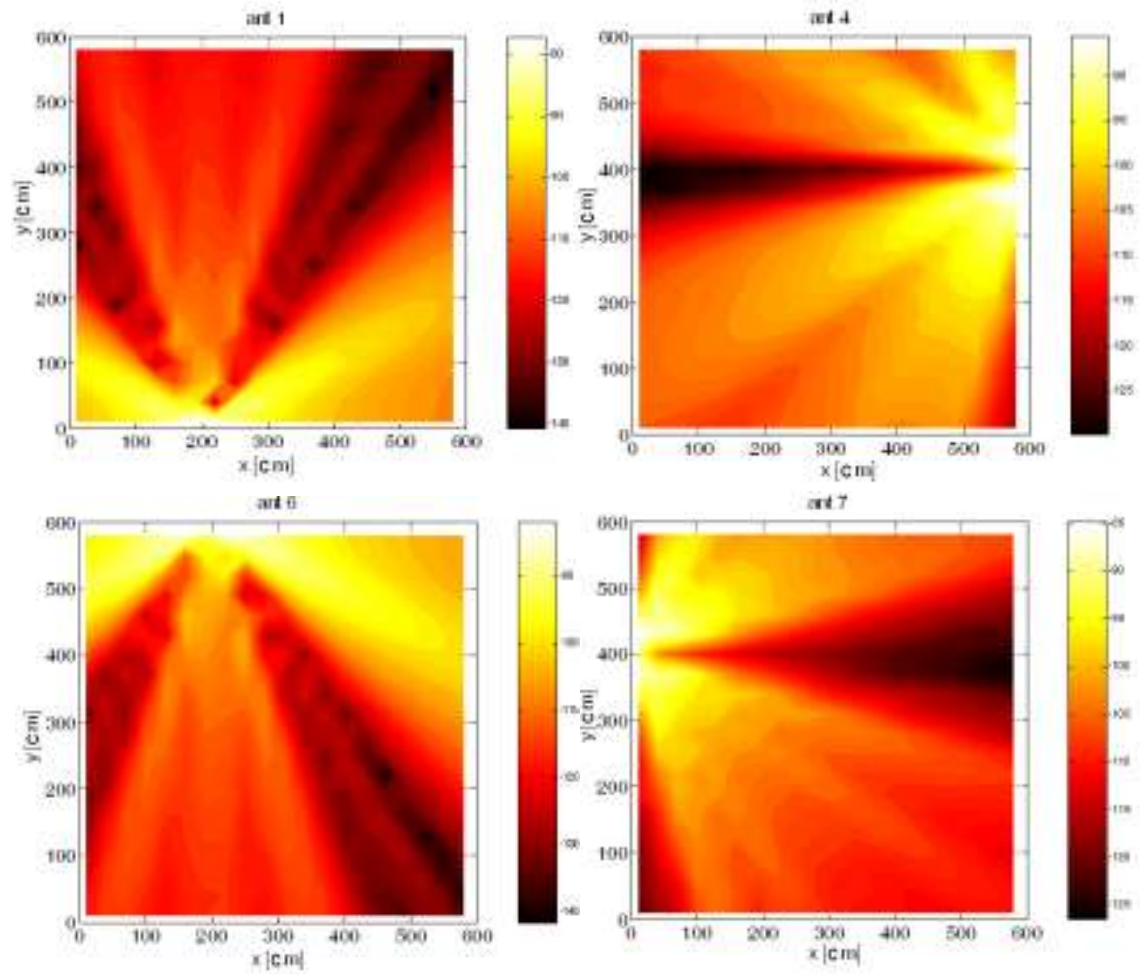

Figure 3 Received signal in logarithmic scale as the tag moved, case $\mathrm{x}$ polarization.

For the sake of simplicity we restrict our attention for cases the antennas and tag are located on the same $\mathrm{z}$ level, and no other structures, including walls, floor and ceiling, exist. At first, we calculate the received signals if the tag is oriented in $\mathrm{x}$ direction, i.e. the tag antenna has $\mathrm{x}$ polarization. With the variation of the position of the tag in the observed region we get certain patterns of received power level, Figure 3 shows the patterns. The pattern for antenna 1 and 6 is identical, also antenna 4 and 7. 

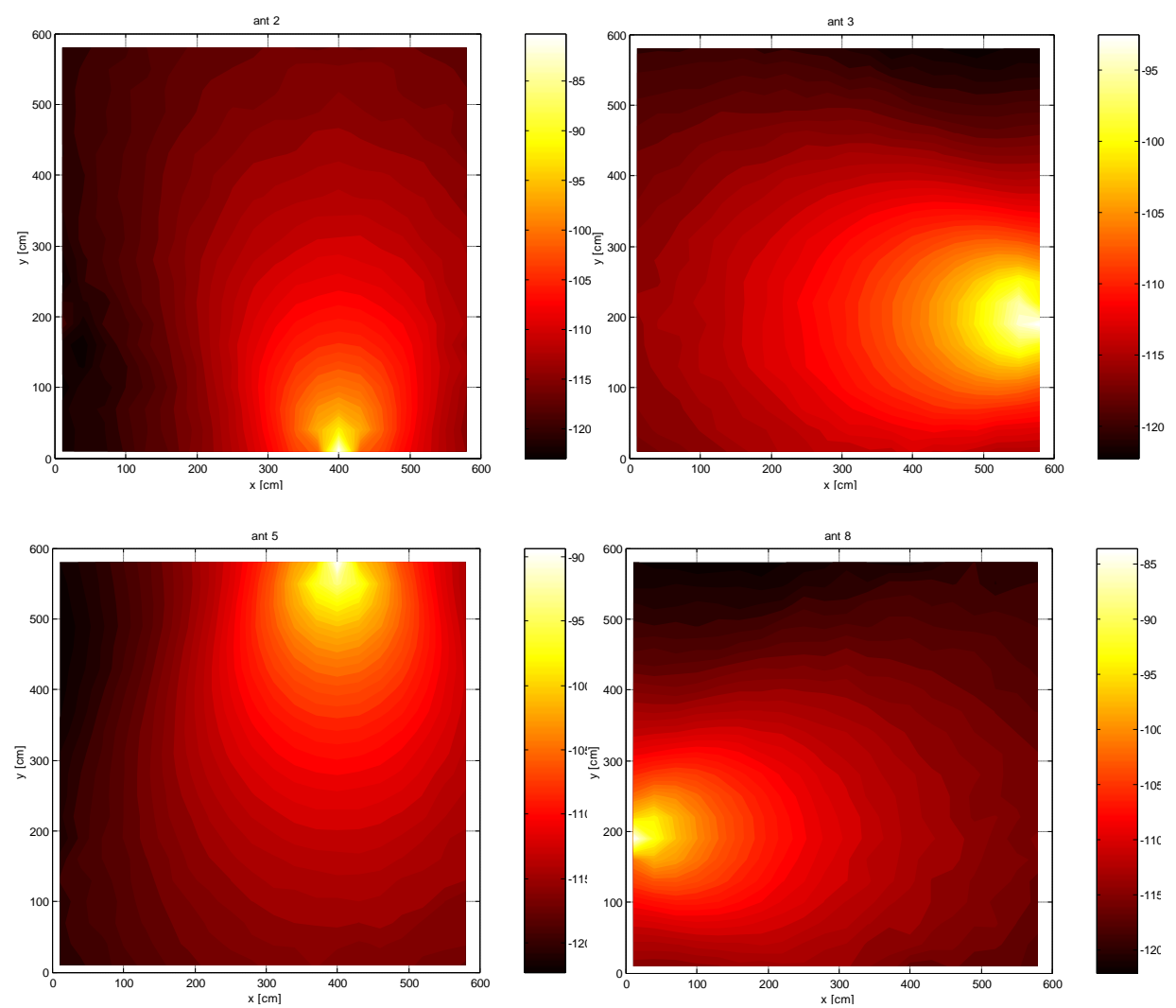

Figure 4 Received signal in logarithmic scale as the tag moved, case $\mathrm{z}$ polarization.

For $\mathrm{x}$ polarization we see due to orthogonal polarization between tag and ant 4 at the position $\mathrm{y}=400 \mathrm{~cm}$, just little power will be received. The similar condition can be also found for antenna 7 . The received power by antenna 1 and antenna 4 forms certain pattern, which shows constructive and destructive superposition. For tag polarization in $\mathrm{z}$ direction, we have the result as depicted in Figure 4. For $\mathrm{z}$ polarization we see a regularity of the received power due to the fact that in this case the radiation diagram is omnidirectional. For the next observation, we concentrate in the case x polarization, as depicted in Figure 3.

The received power level is stored in a data base as reference for next observation. The data base consists of $20 \mathrm{x} 20$ locations which are distributed in $\mathrm{x}=10 \mathrm{~cm}, 40 \mathrm{~cm} \ldots 580 \mathrm{~cm}$ and $\mathrm{y}=10 \mathrm{~cm}, 40 \mathrm{~cm} \ldots 580 \mathrm{~cm}$ coordinates. For each point, four received power for antenna 1, 4, 6 and 7 are stored.

As first observation we get from calculation or measurement the received powers in five different positions (Table 2). 
Table 2 Received power level in $\mathrm{dB}$.

\begin{tabular}{ccccc}
\hline Position & E1 & E4 & E6 & E7 \\
\hline 1 & -110.2136 & -118.5759 & -119.3340 & -96.4848 \\
2 & -113.9358 & -115.8192 & -108.9555 & -97.3702 \\
3 & -110.6494 & -112.7481 & -108.5639 & -99.2522 \\
4 & -113.9911 & -109.3802 & -108.9351 & -104.7876 \\
5 & -110.0855 & -106.1732 & -120.0083 & -109.9018 \\
\hline
\end{tabular}

The search algorithm through the data base delivers the result as shown in Tables 3 and 4. In the tables, for each position, we propose four points available in the data base with nearest received power (minimal value of cost function).

Table 3 Results with cost function 1.

\begin{tabular}{|c|c|c|c|c|}
\hline Position & Point $1\left(1 \times 10^{-5}\right)$ & Point $2\left(1 \times 10^{-5}\right)$ & Point $3\left(1 \times 10^{-5}\right)$ & Point $4\left(1 \times 10^{-5}\right)$ \\
\hline 1 & $100,340(0)$ & $130,430(0.13)$ & $100,400(0.26)$ & $160,340(0.27)$ \\
\hline 2 & $160,340(0.11)$ & $130,340(0.20)$ & $130,520(0.20)$ & $100,310(0.21)$ \\
\hline 3 & $190,340(0.08)$ & $130,370(0.20)$ & $130,310(0.22)$ & $100,280(0.22)$ \\
\hline 4 & $250,340(0)$ & $220,430(0.20)$ & $190,430(0.23)$ & $220,40(0.24)$ \\
\hline 5 & $310,340(0.11)$ & $10,190(0.14)$ & $280,100(0.15)$ & $310,430(0.15)$ \\
\hline
\end{tabular}

Table 4 Results with cost function 2.

\begin{tabular}{ccccc}
\hline Position & Point 1 & Point 2 & Point 3 & Point 4 \\
\hline 1 & $100,340(0)$ & $100,430(0.50)$ & $130,430(0.62)$ & $100,310(0.92)$ \\
2 & $160,340(0.34)$ & $190,340(0.45)$ & $130,340(0.48)$ & $220,340(0.73)$ \\
3 & $190,340(0.12)$ & $220,340(0.32)$ & $130,310(0.37)$ & $130,340(0.58)$ \\
4 & $250,340(0)$ & $220,430(0.53)$ & $220,340(0.55)$ & $250,460(0.58)$ \\
5 & $40,160(0.43)$ & $310,460(0.55)$ & $250,130(0.59)$ & $280,100(0.64)$ \\
\hline
\end{tabular}

We see, positions 1 and 4 are chosen exactly at the positions $x=100 \mathrm{~cm}$, $\mathrm{y}=340 \mathrm{~cm}$ and $\mathrm{x}=250 \mathrm{~cm}, \mathrm{y}=340 \mathrm{~cm}$, respectively. These positions are available and we get exact received powers from calculation or measurement, so that we can refer the position searched to available positions in data base exactly. On the other hand, positions $2: \mathrm{x}=150 \mathrm{~cm}, \mathrm{y}=340 \mathrm{~cm}, 3: \mathrm{x}=200 \mathrm{~cm}, \mathrm{y}=340 \mathrm{~cm}$ and $5: x=300 \mathrm{~cm}, y=340 \mathrm{~cm}$ are not given in data base. If we observe the four positions with minimal cost functions for each there three points in detail.

Figures 5 and 6 show graphically the positions of point candidates by evaluating the cost function 1 and 2, respectively. 


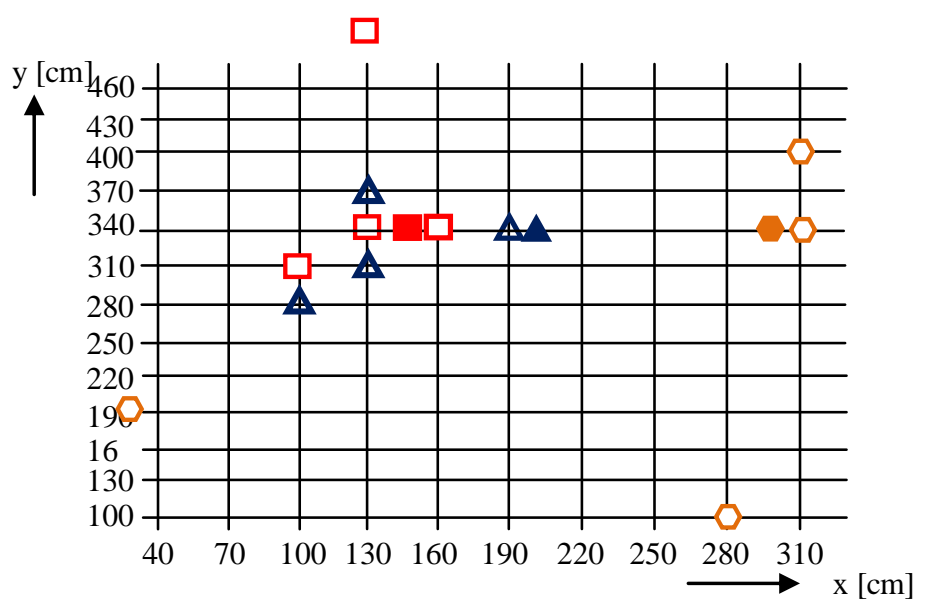

Figure 5 Positions of candidates with cost function 1.

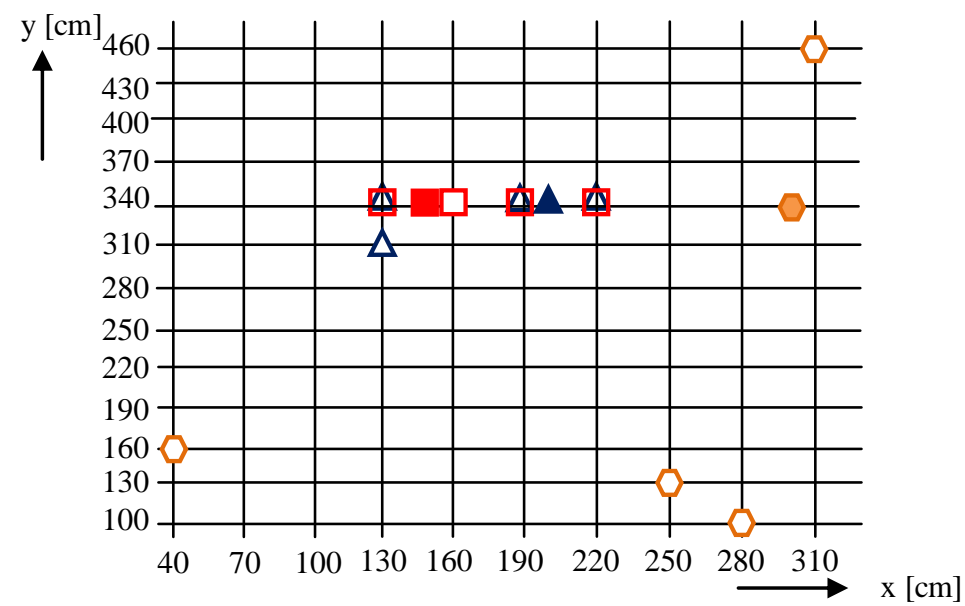

Figure 6 Positions of candidates with cost function 2.

The filled symbols represent the actual positions of the tag. The empty symbols are the candidates of points obtained by calculating the cost functions having smallest values. We see the cost function 2 (Figure 6) gives relative better results, because the candidates of point are close to each other.

For positions 2 and 3 we have rather good approximation positions, however for position 5 , the position of the candidates are scattered away from the correct position. 


\subsection{Scenario with Two Metallic Disturbances}

As extension of the previous observation, here, we would like to direct our attention to more realistic environments. Inside or near the observation region, there are two metallic boxes as disturbances (Figure 7). For the positioning purposes, three directive antennas, i.e. antennas with planar reflector, are used. The antennas are arbitrary located and oriented.

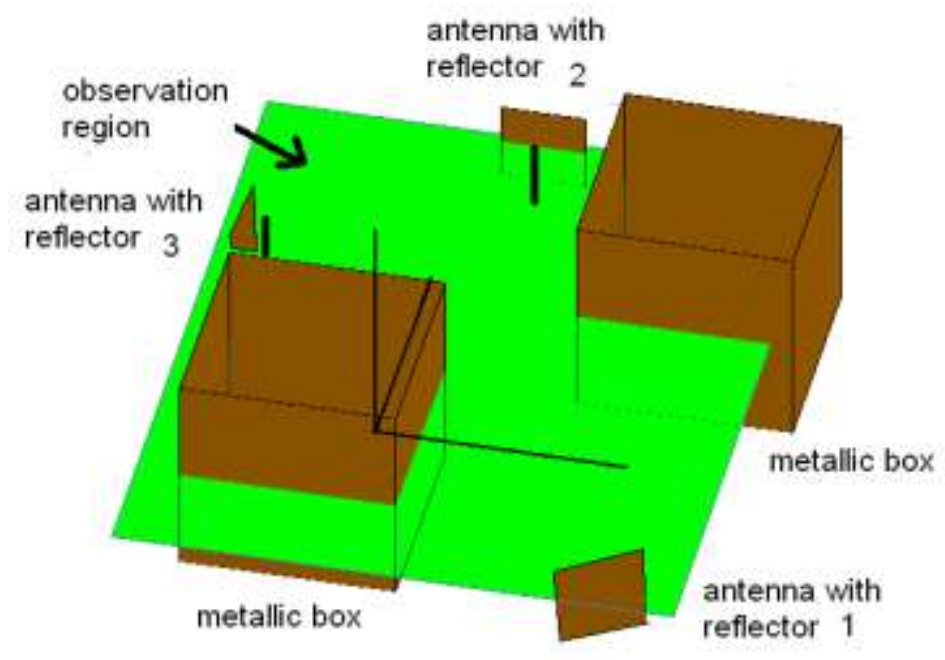

Figure 7 Positioning in scattered region (two metallic disturbances).

For the sake of implementing the fingerprinting procedure, the electric field intensity of each antenna in observation region is calculated. Due to the reciprocity characteristics of propagation, it can be assumed as received electric field by the observed antenna. Figure 8 gives the distribution of electric field intensity in the observation region, generated by each antenna.

The observation region is a plane in the symmetrical cut of the geometry, and is bounded by a rectangular border with dimension $1.55 \mathrm{~m}$ x $1.25 \mathrm{~m}$. The electric field intensity is calculated in distance of $0.05 \mathrm{~m}$, so that for each antenna, we have 832 data entries for electric field intensity.

We see the strong deformation of the near field of the antennas due to the existence of the metallic boxes. Regions close to the antenna, or directly illuminated by the antenna received more intensities, than shadowed region. We see also in the figure, double shadowed regions received much lower electric fields. 

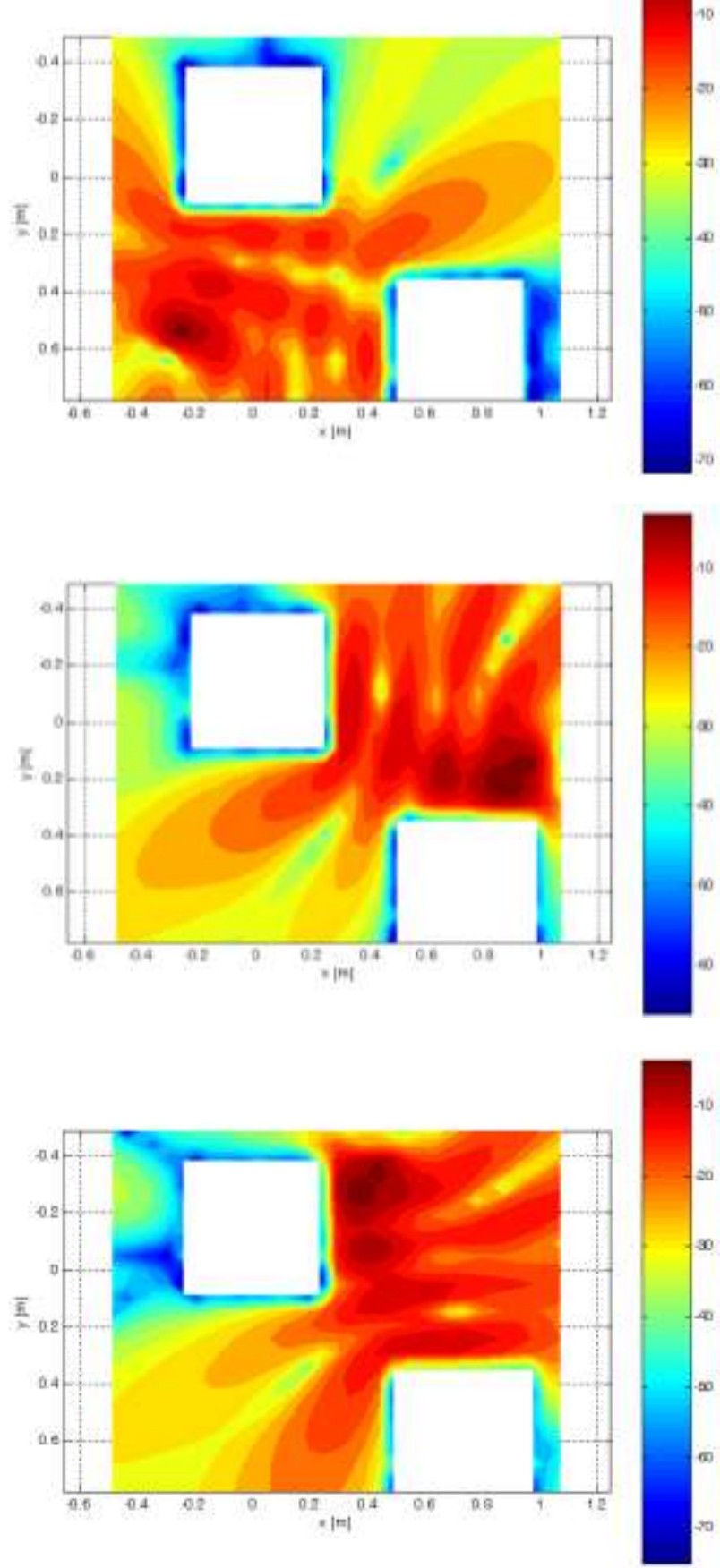

Figure 8 Electric field distribution due to each antenna. 
After obtaining the data base for the environment, we can begin to determine the position of the tag. For this purpose, we let the tag in three different positions arbitrarily. The tag sends back electromagnetic energy to the reader antennas, and with some calibrating the electric power, the received electric field at the reader antennas can be compared to those in data base.

We can simulate, as though we did measurements. The first location of the tag delivers electric fields 20.345, 9.421 and 32.376 at the first, second and third readers, respectively. The second location gives 9.638, 28.081 and 28.629. And the tag at third location sends 56.701, 8.967, and 4.802. This data is considered as perfect measurement results.

Comparing this measurement data with data base by using of Eq. (2), we propose five best results, i.e. results deliver five minimal value of Eq. (2).

Table 5 gives the overview of five best results for each position. The best result has always the function value equal zero. This means, we can find exactly the correct position of the tag. The other results (second to fifth best) are the wrong positions. We see for positions two (triangle down) and three (triangle up), the relative errors are about 0.25 . All points are located in the neighborhood of the correct position (Figure 9). However for position one (circle), the other good results have errors in order of 0.40 , which lead to scattered point positions.

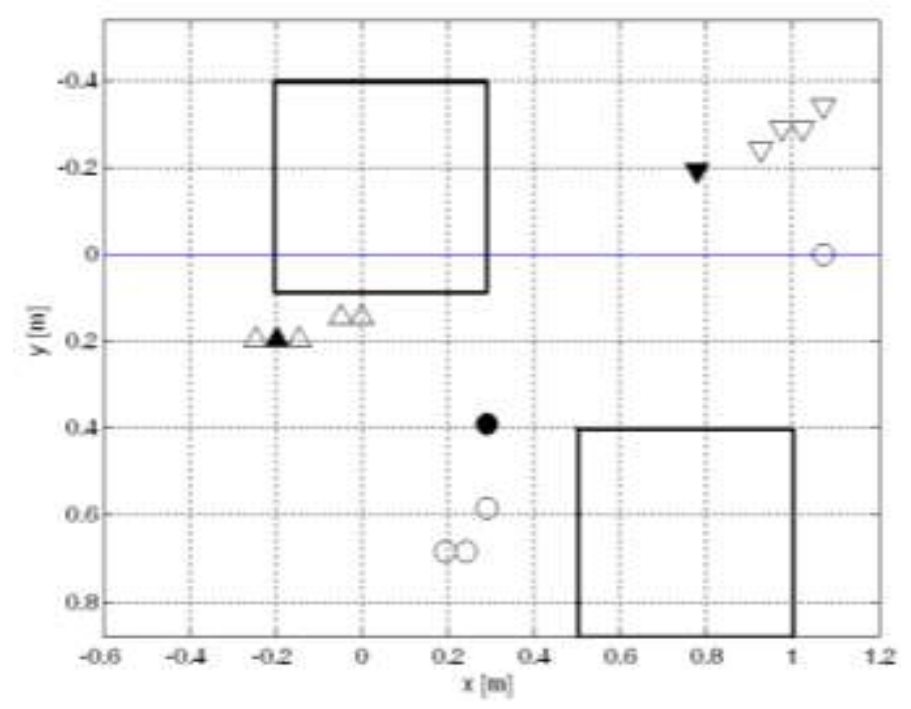

Figure 9 Locations of solution candidates for five minimal function values (Eq. (2)), filled positions are the correct positions - case perfect measurement. 
Table 5 Relative error for perfect measurement data.

\begin{tabular}{cccccc}
\hline Position & First best candidate & Second & Third & Fourth & Fifth \\
\hline Circle & 0 & 0.34 & 0.41 & 0.42 & 0.46 \\
triangle down & 0 & 0.17 & 0.22 & 0.23 & 0.26 \\
triangle up & 0 & 0.25 & 0.25 & 0.28 & 0.28 \\
\hline
\end{tabular}

Next, we observe the effects of imperfect measurements. The obtained measured data should be contaminated by errors, due to imperfect measuring instruments or due to existence of additional disturbances, which are not taken into account in the data base. We vary the measurement data by errors of $-5 \mathrm{~dB}$ to $+5 \mathrm{~dB}$.

Figure 10 shows the positions of each solution due to variations of received electric fields. Variations of field of $\pm 1 \mathrm{~dB}$ and $2 \mathrm{~dB}$ still deliver the correct position, however higher variations shift the positions about $0.25 \mathrm{~m}$ from the correct positions, and for $-4 \mathrm{~dB}$ and $-5 \mathrm{~dB}$ even more than $1.0 \mathrm{~m}$. The errors obtained during the positioning procedures in this more realistic environment are listed in Table 6 .

For position two (triangle down) and three (triangle up), the situation is better. The same variation of received field leads to shifting of about $0.4 \mathrm{~m}$.

Table 6 Relative error for imperfect measurement data.

\begin{tabular}{cccc}
\hline $\begin{array}{c}\text { Error in } \\
\begin{array}{c}\text { ceasurement } \\
(\mathbf{d B})\end{array}\end{array}$ & Circle & $\begin{array}{c}\text { Triangle } \\
\text { down }\end{array}$ & $\begin{array}{c}\text { Triangle } \\
\text { up }\end{array}$ \\
\hline-5 & 0.15 & 0.23 & 0.15 \\
-4 & 0.11 & 0.20 & 0.10 \\
-3 & 0.11 & 0.12 & 0.09 \\
-2 & 0.22 & 0.25 & 0.16 \\
-1 & 0.20 & 0.20 & 0.13 \\
0 & 0 & 0 & 0 \\
1 & 0,20 & 0.07 & 0.19 \\
2 & 0.40 & 0.15 & 0.16 \\
3 & 0.36 & 0.07 & 0.13 \\
4 & 0.39 & 0.09 & 0.08 \\
5 & 0.43 & 0.20 & 0.11 \\
\hline
\end{tabular}



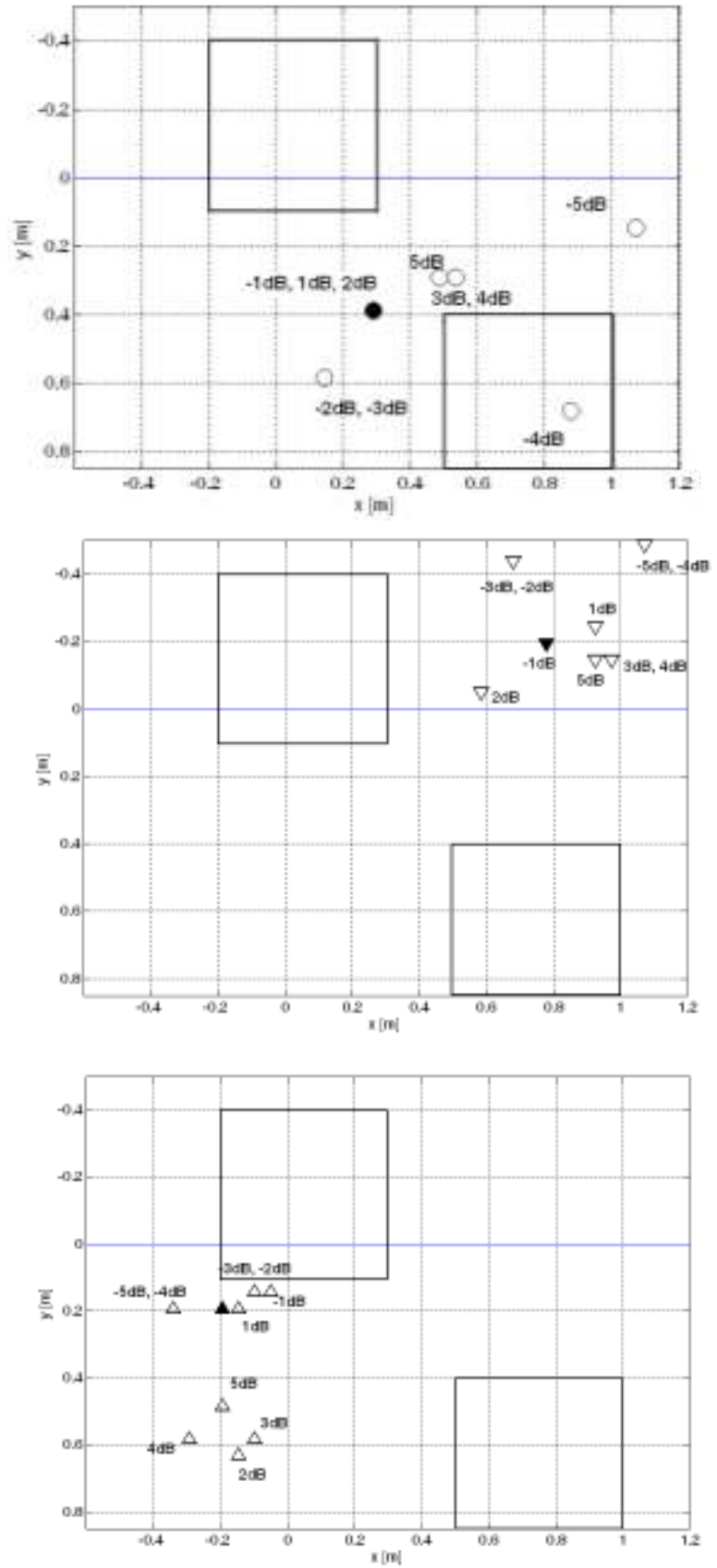

Figure 10 Locations of solution candidates for five minimal function values (Eq. (2)), filled positions are the correct positions $(0 \mathrm{~dB})$ - case imperfect measurement. 


\section{Conclusions}

The polarization and diagram radiation of the antenna (reader and tag) play significant role in producing the pattern of received signal level. We show preliminary results according to effects of polarization and radiation diagram of antennas to field pattern, and consequently to positioning mechanism. We observe also the effects of metallic disturbances around the tag to be positioned. If the measurement gives perfect values or just small deviating, the correct position of the tag can be also recovered.

\section{References}

[1] Finkenzeller, K., RFID Handbuch, 5.ed. Hanser Verlag, Heidelberg, 2008.

[2] Banks, J., Pachano, M., Thompson, L. \& Hanny, D., RFID Applied, Wiley, New Jersey, 2007.

[3] Lim, H.S., Choi, B.S. \& Lee, J.M., An Efficient Localization Algorithm for Mobile Robots Based on RFID System, SICE-ICASE International Joint Conference, Busan, Korea, pp. 5945-5950, 2006.

[4] Wada, T., Uchitomi, N., Ota, Y., Hori, T., Mutsuura, K. \& Okada, H., A Novel Localization Scheme for Passive RFID Tags; Communication Range Recognition (CRR), IEEE International Conference on RFID, pp. 163-169, 2009.

[5] Park, Y., Lee, J.W. \& Kim, S.W., Improving Position Estimation on RFID Tag Floor Localization Using RFID Reader Transmission Power Control, IEEE International Conference on Robotics and Biomimetics, Thailand, pp. 1716-1721, 2008.

[6] Vossiek, M., Wiebking, L., Gulden, P., Wiehardt, J., Hoffmann, C. \& Heide, P., Wireless Local Positioning, IEEE Microwave Mag., 4(4), Dec. pp. 77-86, 2003.

[7] di Flora, C., Ficco, M., Russo, S. \& Vecchio, V., Indoor and Outdoor Location Based Services for Portable Wireless Devices, Proc. $25^{\text {th }}$ IEEE International Conference on Distributed Computing Systems Workshops, 2005.

[8] Muthukrishnan, K., Lijding, M.E. \& Havinga, P.J.M., Towards Smart Surroundings: Enabling Techniques and Technologies For Localization, Proc. International Workshop on Location-and Context-Awareness, Berlin, Germany, 2005.

[9] Taylor, G. \& Blewitt, G., Intellegent Positioning, Wiley, West Sussex, England, 2006.

[10] Gu, Y., Lo, A. \& Niemegeers, I., A Survey of Indoor Positioning Systems for Wireless Personal Networks, IEEE Communications Surveys and Tutorials, 11(1), pp. 13- 32, 2009. 
[11] Ishiwatari, Y., Horigome, H. \& Kobayashi, Y., A Wireless LAN-Based Solution for Issues Related to Positioning Information is Increasingly Desirable, NEC Technical Journal, 2(2), pp. 80- 84, 2007.

[12] Bouet, M. \& dos Santos, A.L., RFID Tags: Position Principles and Localization Techniques, Wireless Day 2008 (WD08), pp. 1-5, 2008.

[13] Zhang, Y., Amin, M.G. \& Kaushik, S., Localization and Tracking of Passive RFID Tags Based on Direction Estimation, International Journal of Antennas and Propagation, Hindawi Publishing Co., pp. 1-9, 2007.

[14] Deyle, T., Kemp, C.C. \& Reynolds, M.S., Probabilistic UHF RFID Tag Pose Estimation with Multiple Antennas and A Multipath $R F$ Propagation Model, IEEE/RSJ International Conf. on Intelligent Robots and Systems, Nice, France, pp.1379-1384, 2008.

[15] Luo, R.C., Chuang, C.-T. \& Huang, S.-S., RFID-Based Indoor Antenna Localization System Using Passive Tag and Variable RF-Attenuation, The $33^{\text {rd }}$ annual conf. of the IEEE Industrial Electronics Society, pp. 2254-2259, 2007.

[16] Kanan, R. \& Azizi, A., UHF RFID Transponders Antenna Design for Metal and Wood Surfaces, IEEE international conference on RFID, pp. 270-277, 2009.

[17] Tanaka, Y., Umeda, Y., Takyu, O., Nakayama, M. \& Kodama, K., Change of Read Range for UHF Passive RFID Tags in Close Proximity, IEEE international conference on RFID, pp.338-345, 2009.

[18] Nikitin, P.V. \& Rao, K.V.S., Antennas and Propagation in UHF RFID Systems, IEEE international conf. on RFID, pp.277-288, 2008.

[19] Alaydrus, M., Effects of Polarization and Radiation Diagram of Antennas in RFID Systems for Positioning Purposes, International Conference on Instrumentation, Communications, Information Technology and Biomedical Engineering (ICICI-BME), Bandung, November 23-25 2009.

[20] Bensky, A., Wireless Positioning Technologies and Applications, Artech House, Norwood, MA., 2008.

[21] Munoz, D., et al., Position Location Techniques and Applications, Academic Press, Burlington, MA, 2009.

[22] Balanis, C., Antenna Theory, $3^{\text {rd }}$ ed. Wiley, New Jersey, 2005. 